\title{
KẾT QUẢ BƯớC ĐẦU PHẪU THUẠT FONTAN TẠI TRUNG TÂM TIM MẠCH - BỆNH VIỆN E
}

\section{Đỗ Anh Tiến*, Nguyễn Công Hụu*, Nguyễn Trần Thuy”, Lê Ngọc Thành*}

\section{TÓM TẮT}

Phẫu thuật Fontan là nối trực tiếp tĩnh mạch hệ thống với động mạch phổi, phẫu thuật được chỉ định cho bệnh nhân (BN) tim bẩm sinh phức tạp, dạng tổn thương một buồng tâm thất. Tại Trung tâm tim mạch Bệnh viện $\mathrm{E}$ đã phẫu thuật Fontan cho $6 \mathrm{BN}$, với kết quả: $4 \mathrm{BN}$ tốt, $1 \mathrm{BN}$ phải mổ lại để mở cửa sổ, $1 \mathrm{BN}$ tử vong trong mổ. Thông báo kết quả sớm là mục đích của nghiên cứu này.

\section{SUMMARY}

The Fontan procedure is total cavopulmonary connection. This technique is application for all forms of single ventricle hearts. In CardioVascular Center E Hospital, there were 6 patients with complex congenital heart diseases who was underwent Fontan procedure; 4 patients with good result, 1 patient was refenestration, 1 intraoperative death. The early results of this report is the purpose of our study.

\section{ĐẶT VẤN ĐỀ}

Phẫu thuật Fontan là nối trực tiếp tĩnh mạch hệ thống với động mạch phổi. Phẫu thuật được Fontan thực hiện đầu tiên năm 1968 cho BN được chẩn đoán thiểu sản van ba lá với miệng nối ở trong tim [1],[3],[5]. Đến năm 1988 Humes và Nawa tiến hành cải biến phẫu thuật Fontan với miệng nối ngoài tim bằng mạch nhân tạo (Extracardiac conduit), và hiện nay kỹ thuật này được sử dụng rộng rãi trên thế giới[5].

Tại Trung tâm tim mạch Bệnh viện $\mathrm{E}$, nhiều BN tim bẩm sinh phức tạp dạng một thất đã được làm phẫu thuật Glenn. Chúng tôi bắt đầu tiến hành phẫu thuật Fontan với miệng nối ngoài tim bằng mạch nhân tạo cho $\mathrm{BN}$ tim bẩm sinh tổn thương dạng một tâm thất.Thông báo kết quả bước đầu là mụch tiêu của bài viết này.

\section{ĐỐI TƯợNG VÀ PHƯƠNG PHÁP NGHIÊN CÚU}

Nghiên cứu $6 \mathrm{BN}$ đầu tiên được làm phẫu thuật Fontan, các dữ liệu nghiên cứu bao gồm: Trước mổ : triệu chứng lâm sàng, siêu âm doppler tim, thông tim, các phẫu thuật tim trước đó. Trong mổ: tuần hoàn ngoài cơ thể, kỹ thuật mổ. Sau mổ: tại phòng hồi sức( thời gian thở máy, thuốc vận mạch...), tại bệnh phòng (lâm sàng, thời gian rút dẫn lưu khoang mang phổi, siêu âm sau mổ).

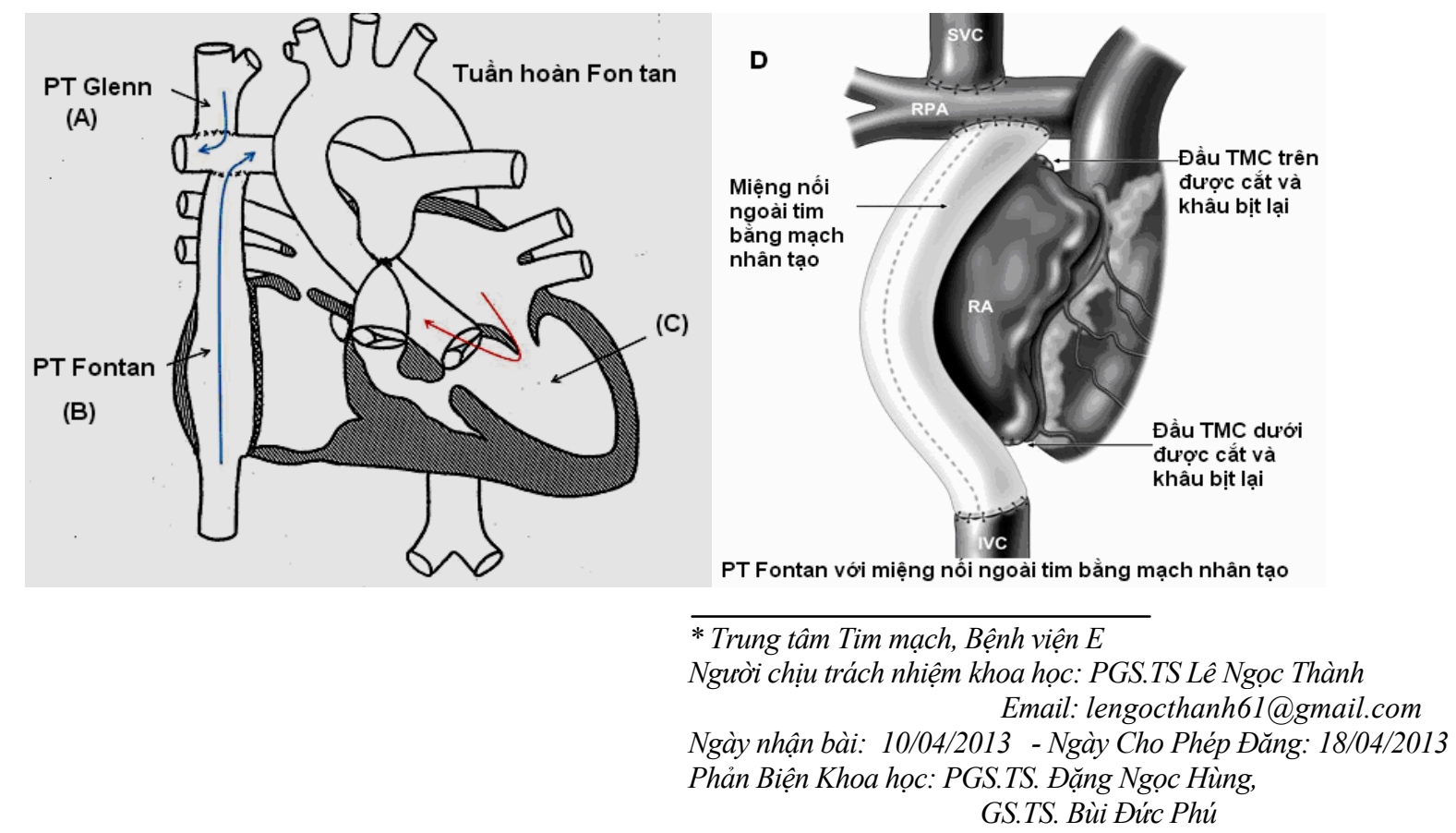


Tuần hoàn Fontan: (A) Phẫu thuật Glenn: Máu tĩnh mạch từ phần trên cơ thể trực tiếp đến phổi. (B) Phẫu thuật Fontan: Máu tĩnh mạch từ phần dưới cơ thể trực tiếp đến phổi. $(\mathrm{C})$ : Máu động mạch từ tâm thất trái bơm qua động mạch chủ đến cơ thể. (D):Thẫu thuật Fontan với miệng nối ngoài tim bằng mạch nhân tạo.

\section{KÊTT QUẢ NGHIÊN CỨU} như sau:

Qua nghiên cứu $6 \mathrm{BN}$ chúng tôi thu được kết quả

Bảng 1: Tuổi, giới tính, cân nặng

\begin{tabular}{|c|c|c|c|c|}
\hline & $\begin{array}{c}\text { Tuổi } \\
\text { (năm) }\end{array}$ & $\begin{array}{c}\text { Giới } \\
\text { tính }\end{array}$ & $\begin{array}{c}\text { Cân } \\
\text { nặng } \\
\text { (Kg) }\end{array}$ & BSA \\
\hline BN 1 & 5 & nam & 12,5 & 0,59 \\
\hline BN 2 & 6 & nam & 12 & 0,78 \\
\hline BN 3 & 7 & nữ & 17 & 0,415 \\
\hline BN 4 & 9 & nũ̃ & 21,5 & 0,87 \\
\hline BN 5 & 9 & nam & 22,5 & 0,89 \\
\hline BN 6 & 14 & nam & 32 & 1,2 \\
\hline
\end{tabular}

Bảng 2: Triệu chứng lâm sàng

\begin{tabular}{|l|c|c|l|}
\hline & $\begin{array}{c}\text { Tím môi, } \\
\text { đầu chi }\end{array}$ & $\begin{array}{c}\text { SpO2 } \\
\text { (\%) }\end{array}$ & Tiền sử phẫu thuật \\
\hline BN 1 & + & 86 & BDG cách 3 năm \\
\hline BN 2 & ++ & 78 & BDG cách 2 năm \\
\hline BN 3 & + & 83 & $\begin{array}{l}\text { BDG, Banding } \\
\text { ĐMP cách 4 năm }\end{array}$ \\
\hline BN 4 & + & 80 & BDG cách 1 năm \\
\hline BN 5 & + & 88 & BDG cách 1 năm \\
\hline BN6 & + & 88 & BDG cách 1 năm \\
\hline
\end{tabular}

(BDG: Bidirectional Glenn: Phẫu thuật Glenn)

Tất cả $\mathrm{BN}$ đều có triệu chứng tím môi, đầu chi. $\mathrm{BN}$ đều được phẫu thuật thì 1 ( BDG) để chuẩn bị cho phẫu thuật Fontan.
Bảng 3: Chẩn đoán, áp lục động mạch phổi đo trên thông tim

\begin{tabular}{|c|c|c|}
\hline & Chẩn đoán & $\begin{array}{c}\text { Ap lục } \mathbf{~} \text { MP } \\
(\mathbf{m m H g})\end{array}$ \\
\hline BN 1 & TA, HRV, VSD & 10 \\
\hline BN 2 & CAVSD, DORV, HLV & 14 \\
\hline BN 3 & DIRL, HLV & 13 \\
\hline BN 4 & TA, HRV & 11 \\
\hline BN 5 & CAVSD, DORV, TGA & 14 \\
\hline BN 6 & DORV, TGA, PVA & 14 \\
\hline
\end{tabular}

(TA: Tricuspid Atresia- Teo van ba lá; HRV: Hypoplastic Right Ventricle- Thiểu sản thất phải; VSD: Ventricular Septal Defect - Thông liên thất; CAVSD: Complete Atrioventricular septal defect Thông sàn nhĩ thất toàn bộ); DORV; Double Outlet Right Ventricle - Thất phải hai đưòng ra; HLV; Hypoplastic Left Ventricle - Thiểu sản thất trái; DIRL: Double Inlet Right Ventricle - Thất phải hai đưòng vào; TGA: Tranposition Great Arterial - Đảo gốc động mạch; PVA: Pulmonary Valve Atresia)

Tất cả $\mathrm{BN}$ đều có tổn thương dạng một tâm thất Bảng 4: Các chỉ số trong mổ

\begin{tabular}{|l|c|c|c|c|}
\hline & $\begin{array}{c}\text { Thòi gian } \\
\text { chạy máy } \\
\text { (phút) }\end{array}$ & $\begin{array}{c}\text { Thò̀i } \\
\text { gian } \\
\text { cặp } \\
\text { ĐMC } \\
\text { (phút) }\end{array}$ & $\begin{array}{c}\text { Kích } \\
\text { thước } \\
\text { mạch } \\
\text { nhân } \\
\text { tạo }\end{array}$ & $\begin{array}{c}\text { Phẫu } \\
\text { thuật } \\
\text { kèm } \\
\text { theo }\end{array}$ \\
\hline BN 1 & 75 & 57 & $18 \mathrm{~mm}$ & \\
\hline BN 2 & 90 & 60 & $18 \mathrm{~mm}$ & \\
\hline BN 3 & 96 & 65 & $20 \mathrm{~mm}$ & DKS \\
\hline BN 4 & 114 & 68 & $20 \mathrm{~mm}$ & Thắt \\
\hline BN 5 & 222 & 174 & $16 \mathrm{~mm}$ & \\
\hline BN 6 & 255 & 69 & $20 \mathrm{~mm}$ & \\
\hline
\end{tabular}

Tất cả $\mathrm{BN}$ đều được sử dụng loại mạch nhân tạo Goretex, dẫn lưu màng phổi. $5 \mathrm{BN}$ được mở cửa sổ giữa mạch nhân tạo và nhĩ phải, $1 \mathrm{BN}$ không mở cửa sổ (BN số 6). 
Bảng 5: Điều trị tại phòng hồi súc

\begin{tabular}{|l|c|c|c|c|}
\hline & $\begin{array}{c}\text { Thò̀i } \\
\text { gian } \\
\text { thở máy } \\
\text { (h) }\end{array}$ & $\begin{array}{c}\text { Thuốc } \\
\text { vận } \\
\text { mạch }\end{array}$ & $\begin{array}{c}\text { Thuốc } \\
\text { lợi } \\
\text { tiểu }\end{array}$ & $\begin{array}{c}\text { Thòi gian } \\
\text { rút dẫn } \\
\text { luu màng } \\
\text { phổi } \\
\text { (ngày) }\end{array}$ \\
\hline BN 1 & 2 & + & + & 7 \\
\hline BN 3 & 9 & - & + & 5 \\
\hline BN 4 & 1,5 & + & + & 3 \\
\hline BN 5 & 40 & + & + & 15 \\
\hline BN 6 & 20 ngày & + & + & 3 tháng \\
\hline
\end{tabular}

Biến chứng trong và sau mổ: $\mathrm{BN}$ số 2 tử vong trong mổ do tuần hoàn bàng hệ nhiều, tăng áp lực động mạch phổi, sau khi ngừng tuần hoàn ngoài cơ thể dẫn đến suy tim cấp BN tử vong. BN số 6: sau mổ thở máy kéo dài, có hội chứng mất protein ruột, xuất huyết tiêu hoá, tràn dịch khoang màng phổi kéo dài, $\mathrm{BN}$ được phẫu thuật lại: mở cửa sổ mạch nhân tạo vào nhĩ phải, sau đó BN ổn định ra viện.

Bảng 6: Triệu chưng lâm sàng và siêu âm tim khi ra viện

\begin{tabular}{|l|c|c|c|}
\hline & $\begin{array}{c}\text { Tím môi, } \\
\text { đầu chi }\end{array}$ & $\begin{array}{c}\text { SpO2 } \\
\text { (\%) }\end{array}$ & $\begin{array}{c}\text { Chênh áp qua } \\
\text { miệng nối duới } \\
\text { (mmHg) }\end{array}$ \\
\hline BN 1 & - & 98 & 0,7 \\
\hline BN 3 & - & 97 & 1 \\
\hline BN 4 & - & 98 & 0,97 \\
\hline BN 5 & - & 94 & 2 \\
\hline BN 6 & - & 93 & 1 \\
\hline
\end{tabular}

\section{BÀN LUẬN:}

Phẫu thuật Fontan được công bố lần đầu tiên năm 1968 và được áp dụng rộng rãi trên thế giới, đến năm 1988 có sự cải tiến kỹ thuật với miệng nối ngoài tim bằng mạch nhân tạo. Chỉ định phẫu thuật Fontan bao gồm: Các tổn thương tim bẩm sinh phức tạp dạng một tâm thất - thiểu sản van nhĩ thất trái, thiểu sản van ba lá, thất trái hoặc thất phải hai đường vào, thiểu sản van động mạch phổi với vách liên thất nguyên vẹn và thiểu sản thất phải, tim hai buồng thất với thiểu sản thất phải hoặc thất trái với thông liên thất, ngoài ra phẫu thuật Fontan còn là một bước trong tiến trình điều trị hội chứng thiểu sản tim trái [1]. Tất cả các $\mathrm{BN}$ của chúng tôi đều có chẩn đoán tim bẩm sinh phức tạp với tổn thương dạng một tâm thất.

Các tác giả trên thế giới đưa ra 10 tiêu chuẩn để lựa chọn BN phẫu thuật Fontan:Tuổi thấp nhất 4 tuổi, nhịp xoang, tĩnh mạch chủ bình thường, thể tích nhĩ phải bình thường, áp lực động mạch phổi trung bình $\leq$ $15 \mathrm{mmHg}$, sức cản phổi $<4$ đơn vị $/ \mathrm{m}^{2} \mathrm{da}$, tỷ lệ đường kính động mạch phổi/ động mạch chủ $\geq 0,75$, chức năng co bóp của thất bình thường $(\mathrm{EF} \geq 0,6)$, van nhĩ thất trái bình thường, các phẫu thuật làm shunt trước đó vẫn tốt [1],[4].

Tất cả $\mathrm{BN}$ của chúng tôi đều $>4$ tuổi, ngày nay theo một số tác giả khác tuổi phẫu thuật của BN đã hạ thấp xuống $>2$ tuổi với lý do để làm giảm tuần hoàn bàng hệ của chủ và phổi ảnh hưởng đến kết quả phẫu thuật về sau, đồng thời khi $\mathrm{BN}$ lớn lên có thể phẫu thuật lại để thay đổi ống mạch nhân tạo (conduit) kích thước lớn hơn [4]. BN của chúng tôi đều được phẫu thuật thì 1 làm phẫu thuật Glenn ( nối tĩnh mạch chủ trên vào động mạch phổi) để chuẩn bị cho phẫu thuật Fontan ( phẫu thuật thì 2). Ở BN tim một thất, tuần hoàn hệ thống và tuần hoàn phổi pha trộn trong tim, phần lớn lưu lượng máu được ưu tiên cho tuần hoàn hệ thống, nhưng cũng có một số trường hợp máu lên phổi nhiều, và hiếm khi tuần hoàn hệ thống và tuần hoàn phổi cân bằng nhau. Vòng tuần hoàn trong phẫu thuật Fontan nó có sự tách biệt giữa tuần hoàn lên phổi với tuần hoàn hệ thống, lúc này tâm thất có nhiệm vụ bơm máu đi nuôi cơ thể. Do vậy để chuẩn bị cho phẫu thuật Fontan, các BN cần có phẫu thuật thì 1 (phẫu thuật Glenn) để giúp cân bằng máu lên phổi và hệ thống, cải thiện sự tiến triển tự nhiên của bệnh, giúp cho $\mathrm{BN}$ thích nghi dần với lượng máu lên phổi nhiều [1],[2],[6]. Thời gian từ khi làm phẫu thuật Glenn đến khi lầm phẫu thuật Fontan thường 6 tháng đến 1 năm. Chúng tôi có $3 \mathrm{BN}(\mathrm{BN}$ số $1,2,3)$ được phẫu thuật Glenn tại các cơ sở phẫu thuật khác nên thời gian tiến hành phẫu thuật thì 2 kéo dài $>2$ năm. BN số 4,5,6 được phẫu thuật Glenn tại bệnh viện của chúng tôi nên sau 1 năm chúng tôi tiến hành phẫu thuật thì 2 (phẫu thuật Fontan) theo các bước của quá trình điều trị. Sở dĩ cần phải phẫu thuật thì 2 sau thì 1 từ 6 tháng đến 1 năm để hạn chế tuần hoàn bàng hệ chủ - phổi do đó giúp bảo vệ phổi tốt hơn, hạn chế tăng áp lực động mạch phổi. 
Tất cả $\mathrm{BN}$ của chúng tôi đều có áp lực ĐMP đo trên thông tim $<15 \mathrm{mmHg}$, tuy nhiên $\mathrm{BN}$ số 2 tử vong trong mổ do tuần hoàn bàng hệ nhiều gây ứ máu phổi, $\mathrm{BN}$ bị phù phổi cấp và tử vong trong phẫu thuật, điều này có thể lý giải do quá trình thông tim đo kết quả không chính xác, đồng thời không chụp động mạch chủ ngực để phát hiện tuần hoàn bàng hệ. Theo Shunji Sano tất cả BN làm phẫu thuật Fontan cần chụp mạch phát hiện tuần hoàn bàng hệ và được bít tuần hoàn bàng hệ bằng dụng cụ trước khi phẫu thuật [4].

$5 \mathrm{BN}$ được mở cửa sổ giữa ống mạch nhân tạo và nhĩ phải, BN số 6 không mở cửa sổ. Hiện nay quan điểm áp lực động mạch phổi bao nhiêu thì mở cửa sổ vẫn còn đang bàn cãi, song với $\mathrm{BN}$ có áp lực động mạch phổi $>15 \mathrm{mmHg}$ ( đây là nhóm $\mathrm{BN}$ có nhiều nguy cơ cao khi phẫu thuật) thì bắt buộc phải mở cửa sổ [3]. BN số 6 của chúng tôi sau mổ có biến chứng: hội chứng mất protein ruột, xuất huyết tiêu hoá, tràn dịch màng phổi kéo dài, $\mathrm{BN}$ được phẫu thuật lại mở cửa sổ, sau mổ $\mathrm{BN}$ ổn định. Chúng tôi thấy rằng trong điều kiện Việt Nam BN thường đến viện muộn, không được quản lí bệnh tốt do vậy phổi không được bảo vệ, đồng thời điều kiện kinh tế khó khăn nên ít $\mathrm{BN}$ được chụp phát hiện và bít tuần hoàn bàng hệ do đó nên mở cửa sổ cho tất cả $\mathrm{BN}$ được phẫu thuật Fontan.

Tất cả $\mathrm{BN}$ của chúng tôi sau mổ trên lâm sàng đều được cải thiện rõ rệt: hết tím môi, đầu chi, hết mệt mỏi khó thở. Trên siêu âm doppler màu miệng nối đều thông tốt, chênh áp qua tĩnh mạch chủ và mạch nhân tạo cũng như giữa mạch nhân tạo và động mạch phổi đều rất thấp. $\mathrm{BN}$ đều có nhịp xoang đều, không có biểu hiện rối loạn nhịp. Tất cả $\mathrm{BN}$ đều được sử dụng thuốc chông đông máu loại chống ngưng tập tiểu cầu (Aspergic) liều thấp trong vòng 6 tháng.

\section{KẾT LUẬN}

Phẫu thuật Fontan lần đầu được áp dụng tại Trung tâm tim mạch Bệnh viện $\mathrm{E}$ cho kết quả tương đối khả quan, giúp điều trị cho các $\mathrm{BN}$ mắc bệnh tim bẩm sinh phức tạp tổn thương dạng một tâm thất đã được làm phẫu thuật Glenn thì đầu ngày càng tốt hơn.

\section{TÀI LIỆU THAM KHẢO}

1. C. van Door and M.R.de Leval: Single Ventricle. Surgery for Congenital Heart Defects. pp 543 - 558.

2. Mudhasudan Gani gara, Atu Pradhu: Extracardiac Fontan Operation after Late Bidirectional Glenn Shunt. Asian Cardiovasc Thorac Ann 18, 2010, pp 253-259

3. Richard A. Jonas: Fenestrated Fontan Procedure. Operative Techniques in Cardiac \& Thoracic Surgery, Vol 2, No3, 1997, pp 229-238

4. Shuji Sano et al: Clinical outcome of the Fontan operation in patients with impaired ventricular funtion. European Journal of Cardio-thoracic Surgery 36, 2009, pp 683-687

5. V. Mohan Reddy, Doff B. Mc Elhinney : Extracardiac Conduit Total Cavopulmonary Anastomosis. Operative Techniques in Cardiac \& Thoracic Surgery, Vol 2, No3, 1997, pp 221-228

6. Vladimir P. Podzolkow et al: Immediate results of bidirectional cavopulmonary anastomosis and Fontan operations in adults. Interactive CardioVascular and Thoracic Surgery 12, 2011, pp 141-146. 